\title{
The Geography of London's Recent Beer Brewing Revolution
}

\author{
Adam Dennett and Sam Page
}

\begin{abstract}
In this paper we examine the recent rapid growth of new breweries in London and the reasons behind it. At the turn of the millennium, just a handful of breweries were operating in London, but by 2016 this number had risen to over 85 . Using open data from the Companies House database augmented with other online and printed sources, we show that the rapid growth of breweries, particularly since 2011, has exhibited spatial patterning. Ripley's K analysis reveals as soon as we see new breweries emerging, they are clustering in space. Cluster analyses reveal that Bermondsey and Hackney are particular locational hotspots for brewing. Closer investigation of the Bermondsey cluster highlights the importance of a number of interacting physical, social and economic factors in helping foster this growth. We show that the railways and the spaces they have created, the general atmosphere of cooperation and sharing surrounding the industry in the city, macro-economic and fiscal changes, foreign influence, technology and markets have all played their part in the recent spatial and temporal evolution of brewing in the city.
\end{abstract}

\section{Introduction}

In the 50 years between the mid-1920s and the mid-1970s, the number of breweries operating in the United Kingdom fell from some 2000 to just 87 (Dixon, 1978; SIBA, 2010). In the 1970s and 80s further closures, takeovers and mergers, combined with changing tastes and drinking habits of the beer drinking populace $^{1}$, meant that some of the most famous and well-established names in British beer, such as Truman's of London, disappeared. By the end of the 1980s, brewing in the UK was dominated by just a handful of large breweries (Knowles and Egan, 2001) producing an increasingly homogenised product. The Campaign

\footnotetext{
${ }^{1}$ Ale and stout accounted for $93 \%$ of sales in 1970, but under $50 \%$ in 1990 as lager increased in prominence (Knowles and Egan, 2001)
} 
for Real Ale (CAMRA) was established in 1971 to try to arrest the decline of the once great British pint, but for many beer drinkers the closure of so many breweries meant the historic diversity and variety in British beer and brewing had been replaced with bland homogeneity.

However, anyone buying a pint of beer in a British pub in recent years may have noticed that the ubiquitous brands of the large multinational beer conglomerates have slowly started to share tap space with a growing variety of alternative producers. It is fair to say that the UK brewing industry has undergone something of a renaissance in recent times. Data from the Society of Independent Brewers (Cabras, 2015) have shown that beer production by its members almost doubled from 2009 to 2014, from 1,721,291 hectolitres to 2,992,747. Data from Companies House (which records all active and some dormant and inactive companies in the UK) documents an almost exponential growth in "Manufacturers of Beer", with a thirteen-fold increase in active breweries in the last 20 years.

While new breweries have sprung up all over the UK, London has played a significant role. Despite its rich brewing history (M. Brown, 2015; Krenzke, 2014), by the early 1990 s only a handful of brewers remained in London ${ }^{2}$ and of those, only two survived into the second decade of the twenty-first century - Fuller Smith and Turner (or Fuller's) located at the Griffin Brewery in Chiswick on the north bank of the Thames; and Young's, on the South Bank of the river at the Ram Brewery in Wandsworth ${ }^{3}$. Of the London breweries operating today only the Meantime Brewery ${ }^{4}$ in Greenwich and Fullers were operating before the turn of the millennium.

Over the last 30 years or so, brewing capacity in the capital has fluctuated. In the 1990s a number of Firkin brewpubs ${ }^{5}$ operated in the city, increasing the volume of beer brewed for a short period, but by the turn of the millennium, the chain had disappeared and along with it the brewing capacity it nurtured. Between 2000 and 2009 a handful of small-scale breweries came and went, but emerging were the first green shoots of the renaissance: over this period the Ha'penny Brewery, Twickenham Fine Ales, Brodies and the Sambrook Brewery were established - all

\footnotetext{
${ }^{2}$ We define London as the area covered by the 32 London Boroughs and the City of London

${ }^{3}$ Young's has since ceased brewing in large volume, but retains a head brewer on the site of the old Ram Brewery, intending to open a new craft brewery as part of a new development on the site in the near future

${ }^{4}$ The original Greenwich Brewery on Penhall Road closed in 2010 and moved to larger premises on Blackwall Lane - http://www.meantimebrewing.com/modern-craft/meantimeline/

${ }^{5}$ Brewpubs are public houses which have small scale brewing facilities on the premises
} 
of whom are still brewing today. 2010 saw the incorporation of some established pioneers of the new scene: the Camden Town, Kernel, Moncada, Redemption and Redchurch breweries. However, there were still only 24 breweries and brewpubs in the city at the end of the year. From 2011 onwards the number of breweries started to increase rapidly: 45 in existence at the beginning of 2012, 65 at the beginning of 2013, 73 by 2014 and 87 by 2015. In mid-2016, there were some 84 active breweries and brewpubs in the city with more emerging (see supplementary information for an animation of brewery growth and decline between 1800 and 2016).

Brewing is once again popular. But what is really happening and why should this be of concern to geographers? Beer, like wine, is a product where place is of central importance. Terroir and provenance (two inherently spatial concepts) have always played a crucial part in the character and identity of beer. Terroir is more commonly associated with wine (Unwin, 1991), but in the context of brewing relates to the local, regional, national and international differences in the natural environment which lead to variations in the four main beer ingredients: water, malt ${ }^{6}$, hops and yeast. These variations along with different cultural brewing processes lead to a huge variety in beer. While it could be argued that terroir has become less important in recent times as modern brewers have become adept at adjusting the mineral content of water and obtaining different varieties of malt, hops and strains of yeast from all over the world to suit the beer they are making, provenance and its associated identity remain extremely important.

This importance is perhaps exemplified by the very existence of beers like 'London Pride' and present day breweries such as Meantime and Camden Town where place is part of the brand identity. The Brixton Brewery ${ }^{7}$ with beers named after prominent roads in the area such as Electric IPA (Electric Avenue), Coldharbour Lager (Coldharbour Lane) and Atlantic APA (Atlantic Road), is just one of a number of new breweries in London which use local geography both in their company and/or product branding. Indeed, as Schnell and Reese observed when studying small emerging breweries in the USA in the 1990s, microbreweries are often "proudly, idiosyncratically local" (Schnell and Reese, 2003, p. 57).

Brewing and place are so intertwined that Flack (1997) identifies a conscious 'neolocalism' in American microbreweries. This assertion of hyperlocal place could

\footnotetext{
${ }^{6}$ Malt is the name given to partially germinated, dried and then roasted cereal grains. In beer, this grain is usually barley, but it can be brewed with wheat, rye or rice grains.

${ }^{7}$ http://www.brixtonbrewery.com/beta/
} 
be viewed as a retort to the regional and national appropriation of the massproduced and homogenised beers available everywhere (Fosters = Australia, Stella Artois $=$ Belgium, Kronenbourg = France, Carlsberg = Denmark, etc.). It may also be that new locally-conscious breweries are embodying what Flack (1997, p. 38) describes as a 'cultural counter-current' - something that is particularly evident in cities where large internal and international migrant populations may crave localism in response to the feelings of rootlessness they experience as new outsiders.

Regardless of whether these theories are relevant to London, location and provenance can be absolutely key to the establishment of a brand and subsequent marketing potential, and can be one factor (along, of course, with the quality and diversity of the product) in the success of new small-scale breweries (Danson et al., 2015). Geography and place are thus very likely, in one way or another, to play a part in the story of the new brewing revolution in London. This raises some interesting research questions:

1. Where are these new breweries locating, is there any discernible spatial pattern and why are they locating where they do?

2. How has London's brewing renaissance evolved over time and what are the driving forces behind it?

These questions lead to two related research hypotheses which we will test empirically in the remainder of this paper:

1. The geography of brewing in London will reveal much about the underlying factors influencing the recent growth of the industry. Location can be looked at in both relative and absolute terms. Relatively, we might expect that if terroir and local provenance confer some kind of crucial brand advantage, then it is unlikely that breweries will cluster, rather they will be dispersed enough that these advantages can be realised. On the other hand, it may be that the benefits afforded by agglomeration economies (characterised by the sharing of resources such as knowledge, experience and hardware on the input side and customers on the output side) might trump local branding advantages, in which case we would expect clustering to occur. This relative distribution of breweries will give us clues as to which is more important. The absolute location of breweries will largely be determined by factors such as local operational costs and constraints such as rent, the availability of suitable 
space $^{8}$ and access to market; but understanding where in the city breweries are locating will give clues to the importance of these factors as well.

2. The recent growth of brewing in London can be mapped to a timeline of an evolving regime of beer taxation and legislation, the global financial crisis, a shift towards localism in food more generally, and the earlier growth of a thriving craft beer scene in North America. To varying degrees, each of these things is likely to have contributed to an environment where opening a new brewery is both financially viable and has entered the consciousness of some to the extent that it is now seen as a potential career option. We expect that the mapping of the timeline of these events onto that of the growth of brewing in London will begin to hint at their relative importance to the story and help explain some of what we observe.

\section{Data}

Our data come primarily from spatially and temporally referenced records kept by Companies House $^{9}$. These data were cleaned, and then validated and augmented by information from a number of websites ${ }^{10}$, along with a directory of London brewers and breweries since 1650 (M. Brown, 2015) and historic maps from the National Library of Scotland ${ }^{11}$. The final database for this analysis contains entries for 164 breweries and brewpubs which have existed in London between 1431 and 2016. This is far from a complete time-series, but from around 1990 onwards, we are confident that our data are comprehensive.

\footnotetext{
${ }^{8}$ Brewing is a relatively space-intensive industry. Equipment such as mash tuns and fermenting vessels need to be large to accommodate the volumes needed for commercial brewing.

${ }^{9}$ https://www.gov.uk/government/organisations/companies-house

${ }^{10}$ http://www.pubology.co.uk/, http://desdemoor.co.uk/, http://www.quaffale.org.uk/, http://www.londonbrewers.org/ and http://www.beermad.org.uk/

${ }^{11}$ http://maps.nls.uk/geo/explore/
} 


\section{Analysis}

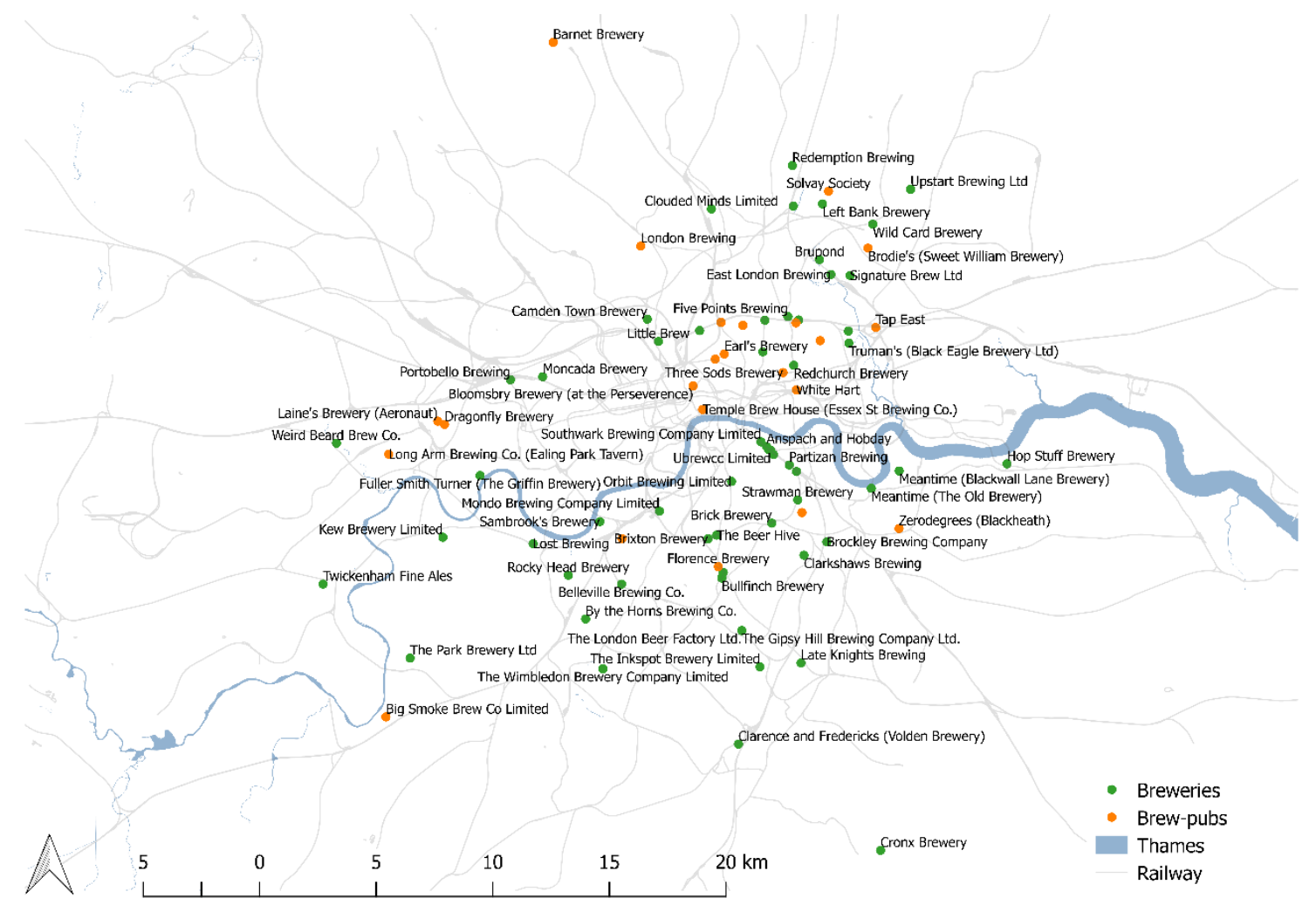

Figure 1 - Location of Breweries in London, 2016

Figure 1 shows the location of every brewery and brewpub ${ }^{12}$ in London appearing in our database at the beginning of 2016, but from this map it is very difficult to discern any real pattern to the distribution of points. One way of determining whether a pattern exists in the data is to compare the observed distribution of points to an idealised random distribution. If the points do not conform to a random distribution, then it is likely that there is some unobserved factor or factors (for example those mentioned in our hypotheses) which could be causing non-random clustering or dispersal to occur. An assessment of the randomness of any point dataset can be carried out using Ripley's $K$ function. The value of $K$ (at a given point in time) is an indication of whether (for a given neighbourhood radius around any brewery of interest) there are more or fewer breweries in the neighbourhood than we would expect under a condition of Complete Spatial Randomness (CSR). CSR is a situation where a collection of points observed in

\footnotetext{
${ }^{12}$ We have included brewpubs because despite the relatively low volume that they brew, they are very much part of the brewing 'scene' in London, perhaps exemplified by a number who are members of the London Brewers Alliance - http://www.londonbrewers.org/members/
} 
space conforms to an expected (Poisson) probability distribution ${ }^{13}$. Where clustering (or dispersal) is observed, then there are likely to be other unobserved factors influencing this clustering. $K$ is calculated using the following formula:

$$
K(r)=\frac{1}{\lambda} \frac{1}{N} \sum_{i \neq j} \sum_{j \neq i} k_{i j} \quad \text { Equation } 1
$$

Where $r$ is the radius of a circle (neighbourhood) around any brewery, $i, \lambda$ is the expected (mean Poisson) intensity of breweries - $\lambda=\frac{N}{S}$ where $N$ is the total number of breweries in London at a given time and $S$ is the total area of London (the area defined by the 32 London Boroughs). $k_{i j}=1$ if the distance between breweries $i$ and $j$ is $\leq r$ and 0 if $>r$.

Ripley's $K$ is sensitive to the boundaries of the study area, but various alterations to the standard formula above can be used to correct for these issues (Brundson and Comber, 2015; Goreaud and Pélissier, 1999). In calculating $K$ here, we make use of the Kest() function in the spatstat package in R (Baddeley et al., 2015) and use 'border' correction to account for the edge of the London study area. In this analysis we have not fully accounted for the areas in the city where breweries cannot possibly exist (such as in public parks, bodies of water, etc.). These are physical constraints which could lead to an artificial impression of clustering. So that an unbiased assessment can be made, we also calculate $K$ for two related activities - manufacturing (taken from the Ordnance Survey's Point of Interest dataset $^{14}$ ), and public houses (obtained from a website maintained by John Adams in the UCL Department of Geography ${ }^{15}$ ). Land-use constraints may lead to some spatial clustering in these activities as well, so if the locations of breweries are more clustered than pubs or other manufacturing industry then this may be evidence of something occurring with brewing to influence this, over and above the physical and planning constraints affecting these related urban activities.

Taking the distribution of breweries in 2016 as a starting point, Figure 2 shows the value of $K$ for neighbourhood radii of up to 2500 metres for breweries, all manufacturing industry and pubs. The red diagonal line represents the value of $K$ at each neighbourhood radius distance under a condition of CSR. Where the observed values of $K$ fall above and to the left of this line, this is indicative of

\footnotetext{
${ }^{13}$ The Poisson distribution describes the probability of a discrete event occurring, given some observed average - in our case, breweries in a particular spatial unit given the average across all such similar units in London.

${ }^{14}$ https://www.ordnancesurvey.co.uk/business-and-government/products/points-ofinterest.html

${ }^{15}$ http://www.ucl.ac.uk/ ccaajpa/pubs-listed.html
} 
clustering at this distance, whereas if the values fall below the line, this is indicative of dispersal.

As seen in Figure 2, values of $K$ indicate that for all radii around breweries between around $100 \mathrm{~m}$ to $1800 \mathrm{~m}$, we can observe more breweries than we would expect to find under a condition of CSR. This clustering is most pronounced at radii of around 500 and 1000 metres - distances that are sufficiently small that we may think of these almost as local neighbourhood level clusters with it only taking around 10-15 minutes to walk 1000 metres. At these relatively short distances, it is highly likely that there will be some interaction amongst the breweries; this might be both direct (talking to each other as they share business interests and a common passion for their product), and indirect (through sharing of customers, suppliers or distributors). Importantly, there appears to be clustering over and above that exhibited by other manufacturing industries and pubs, which suggests that the clustering exhibited is not just an artefact of the limited set of locations within which breweries can operate.

Conducting the same analysis on the patterns of breweries at the beginning of 2013, 2014 and 2015 reveals very similar patterns (not shown), however for years where the total number of breweries in the city is small (1985-2011) there are too few points to carry out a meaningful analysis. We can however conclude that around 2012/2013 when brewing was really starting to take off again within the city, new breweries were not locating randomly; they tended to cluster within distances of around $2 \mathrm{~km}$ of each other. Part of this will have reflected land use constraints, but comparison with general manufacturing and public houses suggests other factors are at play. 


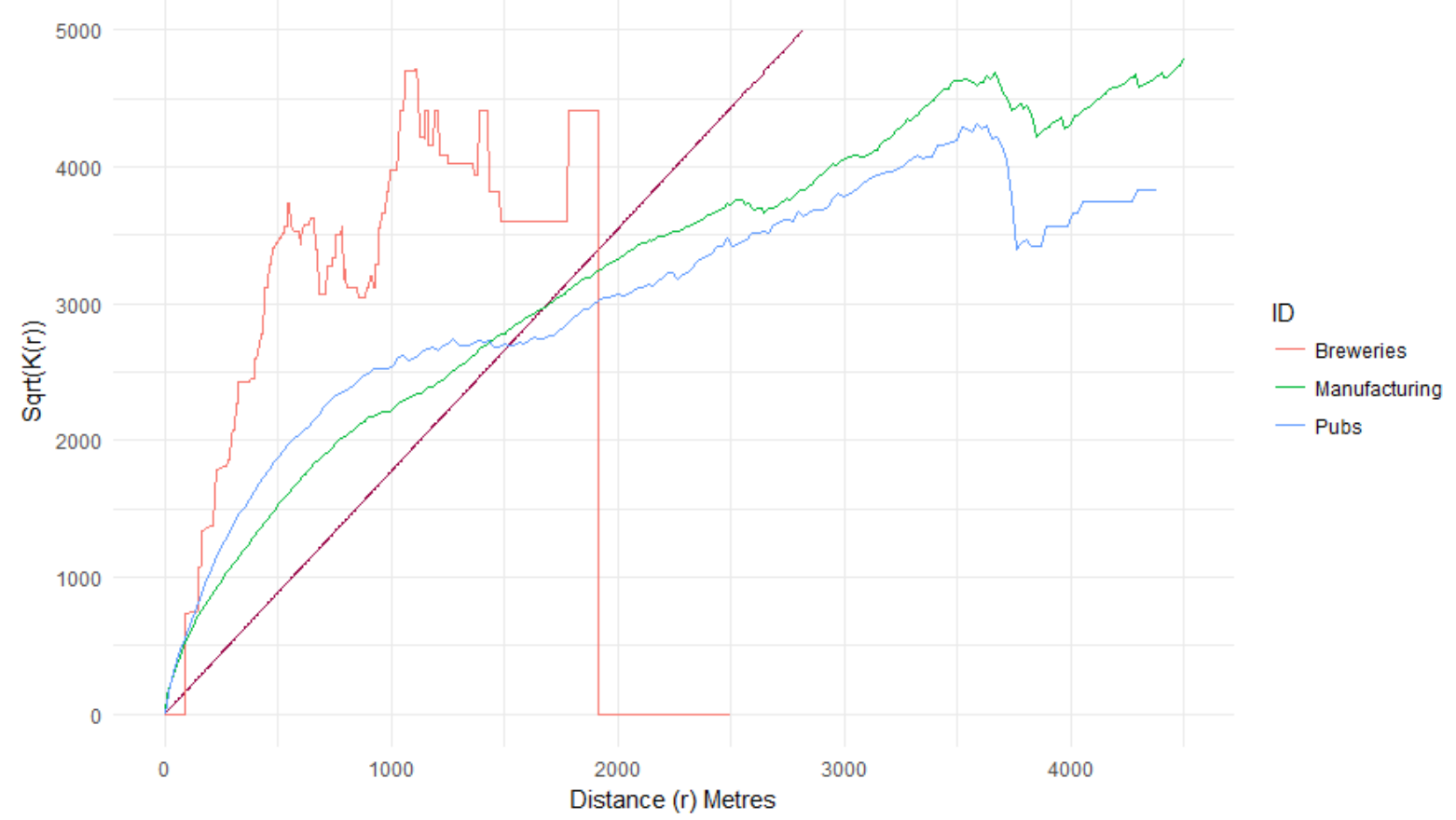

Figure 2 - Values of Ripley's K for London Breweries, Manufacturing and Public Houses 2016

Ripley's $K$ is able to give us a sense that some interesting clustering of breweries is occurring within London from around 2013 onwards, but it is not able to show where this clustering is occurring. In order to get a sense of the geography of brewery clustering, we need to explore some alternative techniques.

Neighbourhood-level spatial dependency was tested using a localised version of Moran's (1950) I statistic (Anselin, 1995). This indicated 'hot-spots' of brewing to the North of the river Thames in an area which comprises the northern edge of Tower Hamlets and the southern edge of Hackney, in particular around Bethnal Green, Dalston and Victoria Park, as well as to the south of the Thames, particularly in the London Bridge / Bermondsey area of Southwark. This analysis is highly susceptible to size, shape and arrangement of the spatial units (the Modifiable Areal Unit Problem; Openshaw, 1984) and so to avoid these issues and verify these potential cluster locations we turn to an alternative technique. If we define our breweries as points on a map, then a variety of methods are available to search for clusters data such as these. The Geographic Analysis Machine (Openshaw et al., 1987) has been used in epidemiology to search for point clusters where suitable populations 'at risk' exist (Openshaw et al., 1988), but for spatial features without associated populations such as breweries, then 
alternative methods are required. Here we use a density-based method called DBSCAN (Ester et al., 1996) implemented in the fpc() package in $R$ (Hennig, 2015). DBSCAN is preferred here over other clustering algorithms methods such as $k$ means as we do not have to pre-specify the number of clusters a priori. The only parameters that need to be pre-specified are an epsilon parameter, which stipulates the radius of a neighbourhood around each point to be clustered, and a minimum points parameter which determines the minimum number of points to be counted within a neighbourhood for a cluster to be identified. The algorithm identifies core/seed points (points with equal to or more than the minimum number of points in its epsilon neighbourhood), border points (points that are in the neighbourhood of a core point, but have fewer than the minimum number of points in their own neighbourhood) and noise/outlier points (those points which are neither core nor border).

Analysing the breweries in 2016, an estimate of a suitable epsilon value can be obtained from the results of the Ripley's K test carried out earlier. Figure 2 shows that clustering is most pronounced at distance radii of around 600 and 1100 metres, so these distances become the initial values of epsilon. The Figures below (3-6) show the results of the DBSCAN analysis for these values of epsilon, with the minimum number of points to consider as neighbours within the epsilon radius varying from 3 to 4 . 


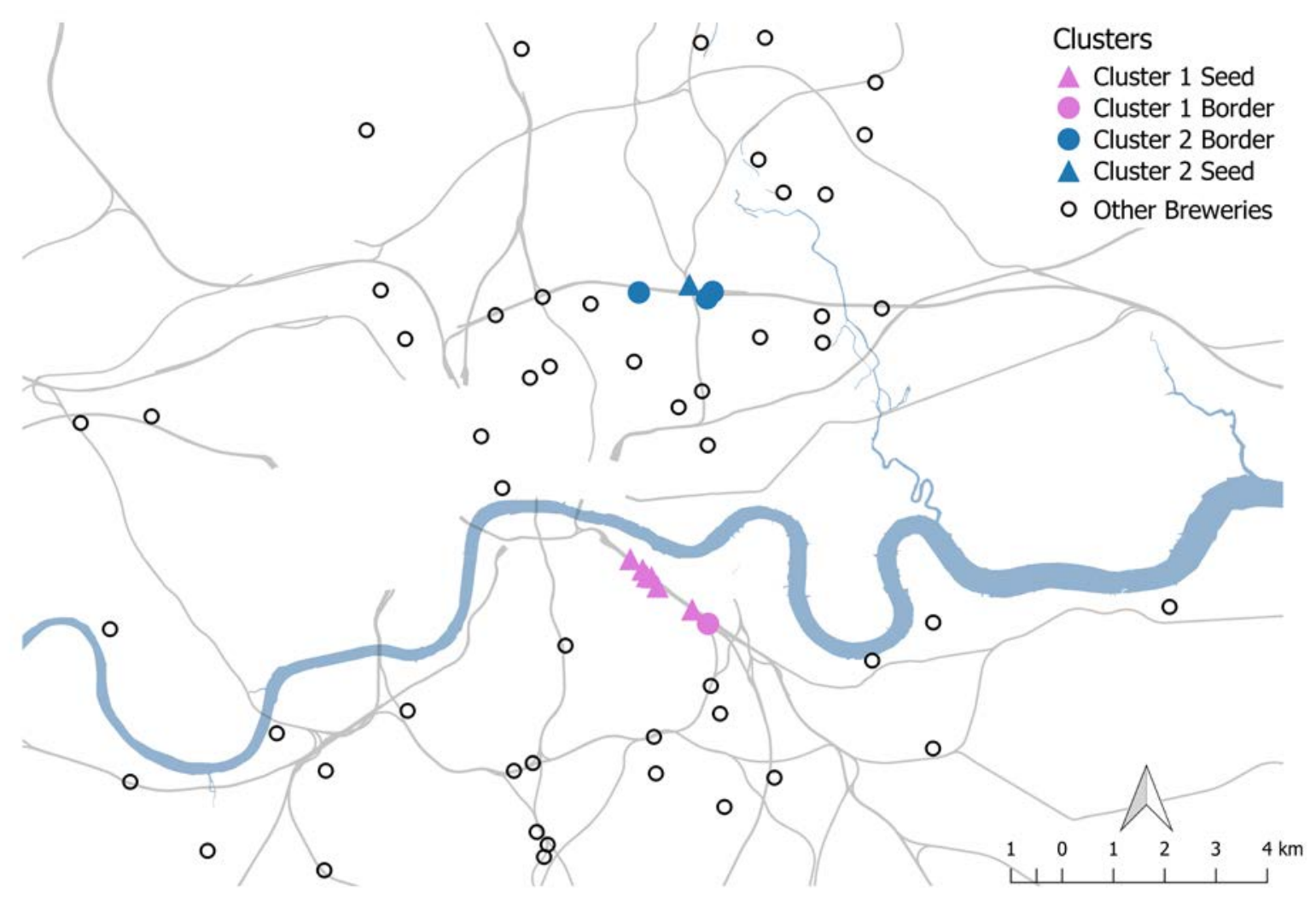

Figure 3 - DBSCAN Clusters, epsilon = 1100, minimum number of neighbouring points $=4$

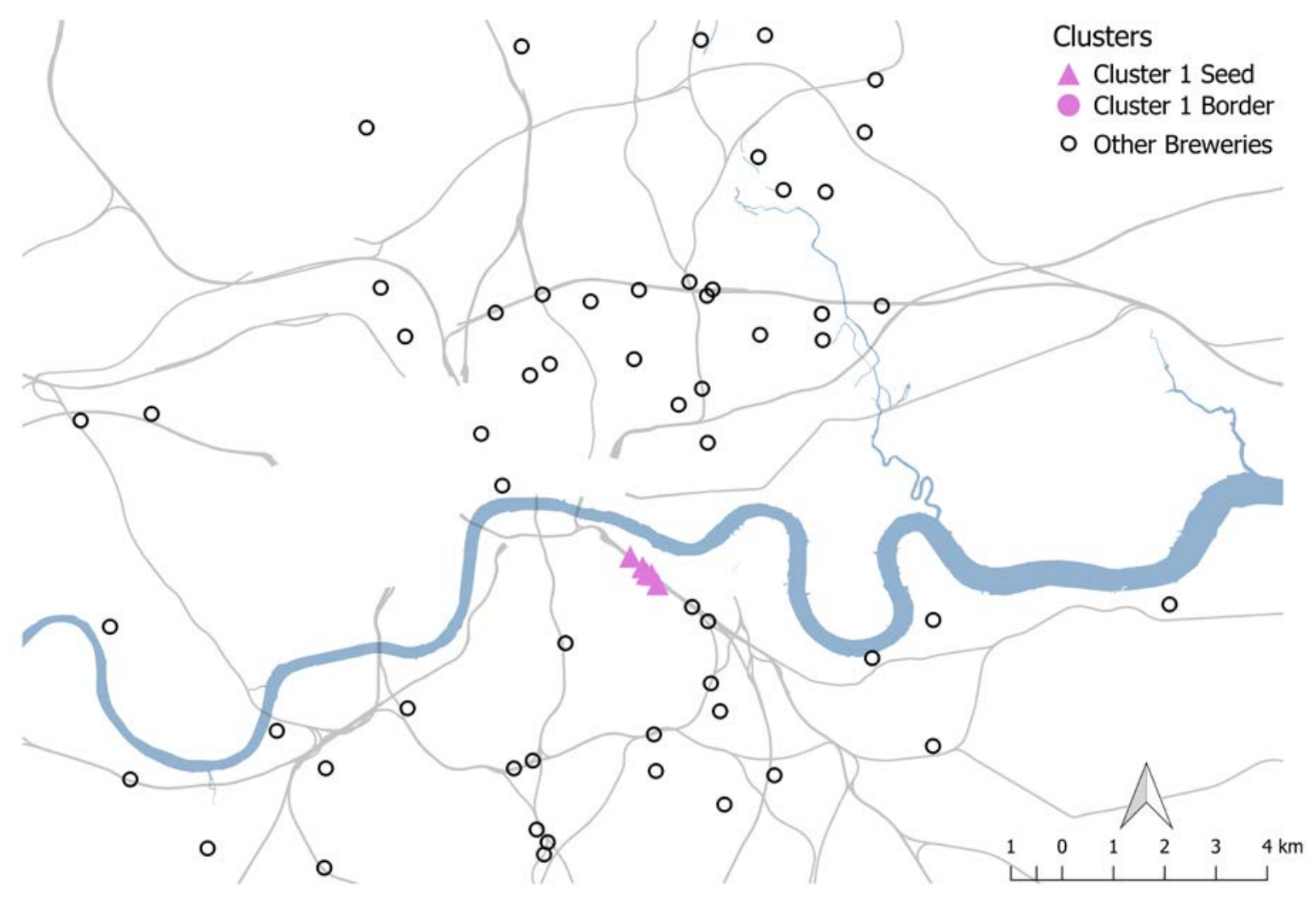

Figure 4 - DBSCAN Clusters, epsilon $=600$, minimum number of neighbouring points $=4$ 


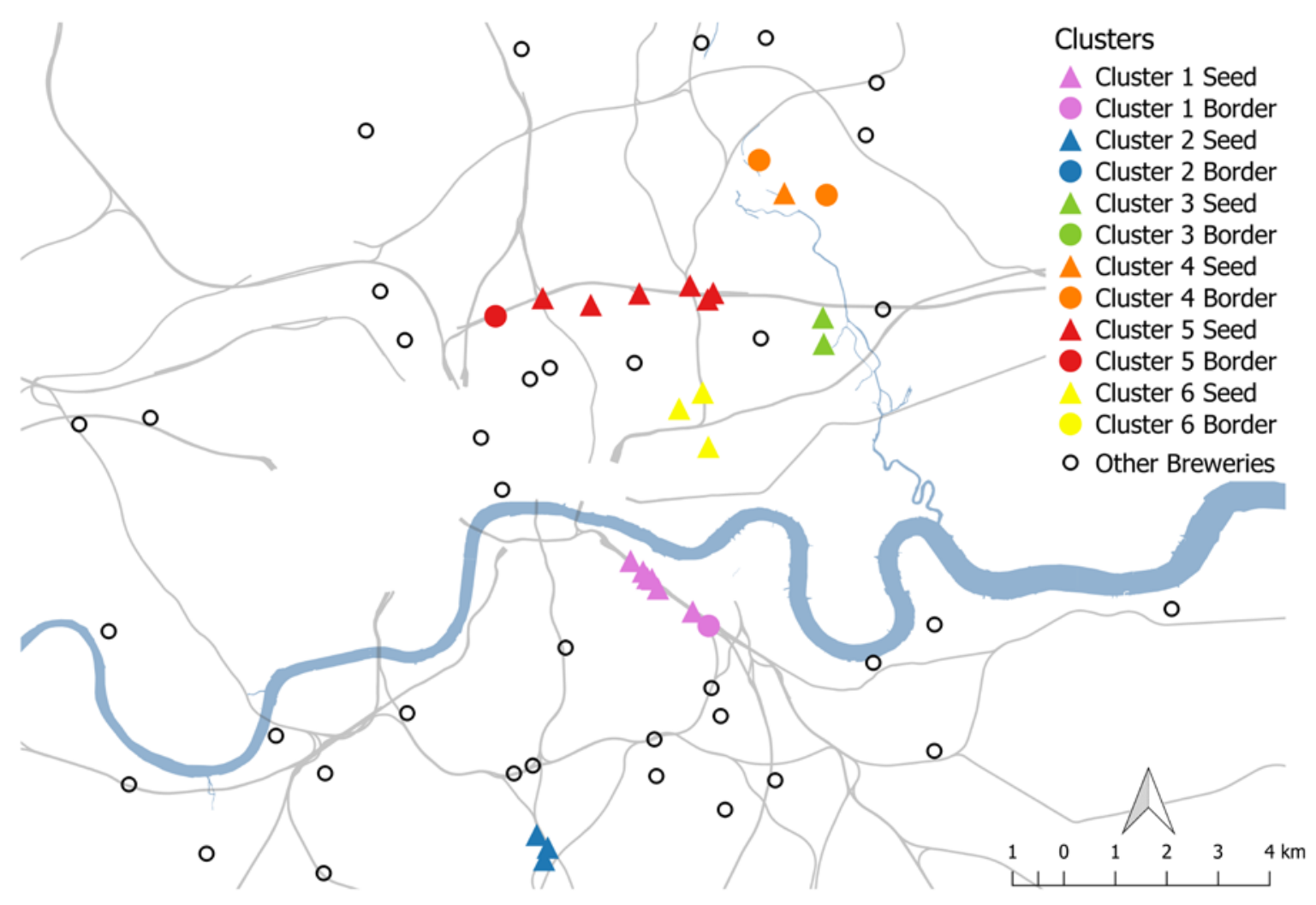

Figure 5 - DBSCAN Clusters, epsilon = 1100, minimum number of neighbouring points $=3$

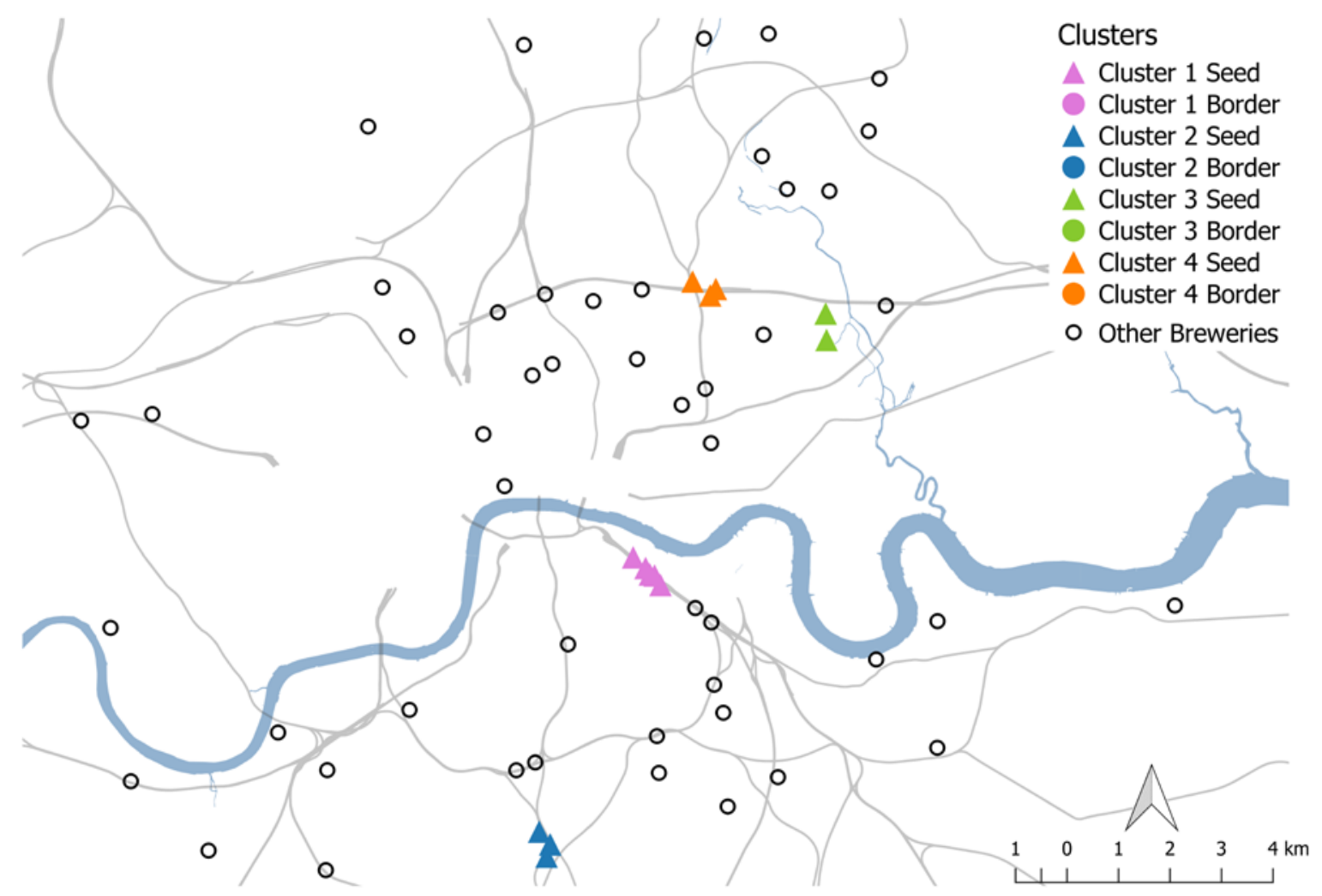

Figure 6 - DBSCAN Clusters, epsilon $=600$, minimum number of neighbouring points $=3$ 
Figure 3 (epsilon $=1100 \mathrm{~m}$, minimum neighbouring points $=4$ ) reveals 2 clusters in the dataset, with Cluster 1 located in Bermondsey, South London and comprising 6 'core' nodes (the Southwark Brewing Company, Anspach and Hobday, Brew By Numbers, Ubrew, the Kernel Brewery and the Partizan Brewery) and a border node (Fourpure). Cluster 2 is to the north of the river in Hackney with the Five Points Brewery acting as the core node with the Pressure Drop Brewery, the Maregade brewery (in the Cock Tavern) and the 40 FT Brewery as border nodes. Figure 4 shows that by keeping the 4 neighbour threshold but reducing the epsilon radius to $600 \mathrm{~m}$, only one cluster remains - the 5 most westerly breweries in the Bermondsey cluster.

Reducing the cluster threshold to 3 neighbours allows other potential clusters to emerge. Figure 5 shows 6 clusters (epsilon $=1100 \mathrm{~m}$, minimum neighbouring points $=3$ ). The Bermondsey cluster remains (Cluster 1 ), as does the Hackney cluster (Cluster 5 in this figure), although it extends quite some way westwards into Islington and incorporates the Hops and Glory and Brewhouse and Kitchen (Highbury) brewpubs and the Hammerton brewery (border node). Four new clusters appear: Cluster 2 to the South around Hearn Hill, incorporating the Bullfinch and Canopy Breweries and the Florence brewpub; Cluster 3 in the East End, including just the Trumans and Crate Breweries; Cluster 4 to the North of the map with the East London Brewing company as the core node and Brupond and Signature Brew as border nodes; and Cluster 6 in Tower Hamlets which includes the Redchurch brewery and the Three Sods and White Hart brewpubs. Reducing the epsilon radius to $600 \mathrm{~m}$ (Figure 6) loses the Tower Hamlets cluster and the small cluster to the North centred on the East London Brewery (clusters 4 and 6 in Figure 5). The Bermondsey cluster remains, (although is reduced in size to those breweries which as furthest west, as in Figure 4), as does the Herne Hill cluster and the small cluster comprising just the Crate and Trumans brewery. The Hackney cluster is once again reduced to just a small cluster.

\section{Discussion}

The analysis above allows us to reach some conclusions in relation to our first research question and hypothesis. Both the local Moran's I and DBSCAN analyses reveal that brewing in London is not randomly distributed in space. It is a central London activity with clusters of breweries emerging in the inner boroughs of Southwark, Tower Hamlets, Islington, Hackney and Lambeth. Ripley's $K$ analysis indicates that clustering/agglomeration is more important than dispersal (or a 
random distribution) and is more pronounced for brewing than for general manufacturing or the location of public houses, and clustering has developed since around 2012 when the brewing industry started to take off again.

This suggests that the potential advantages of a hyperlocal identity are less important than factors which lead to agglomeration (certainly in the centre of the city). Many brewers still brand using neighbourhood identities, but it would appear that where a number of breweries cluster together and neighbourhood branding disappears, 'London' is still a prominent locational branding tool and this seems to suffice. Spatial analysis cannot tell us what these agglomeration factors are, why the breweries are locating precisely where they do and what the driving forces are behind their emergence in recent years. A number of factors are likely to be at play and while the experience of breweries is not universal, in analysing the strongest (most frequently occurring) cluster as our case study example, we can visit many of the influencing factors that play some role in the story of other breweries in the city. As such, we turn our attention to Bermondsey. 


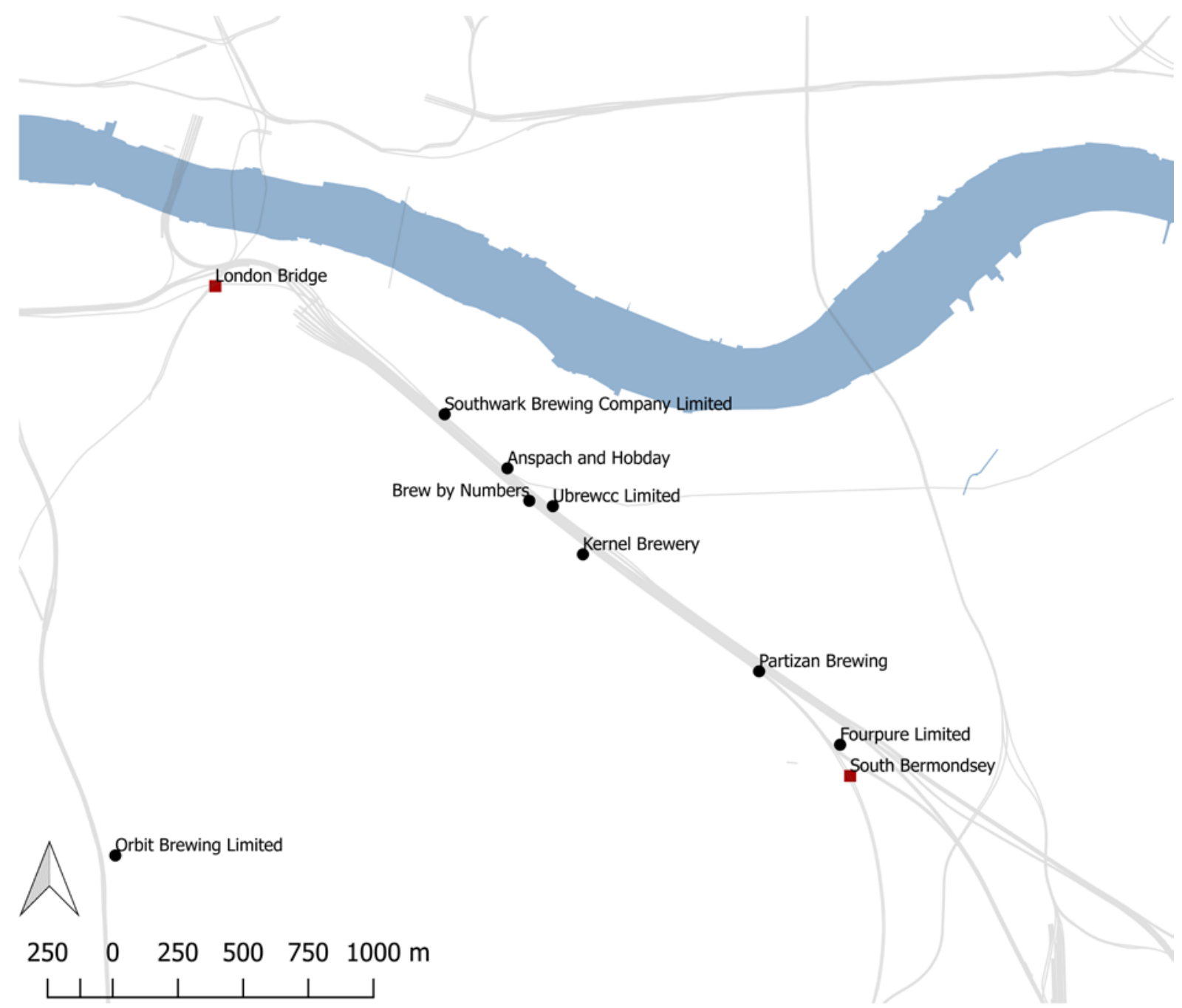

Figure 7 - The Bermondsey 'Beer Mile'. The square symbols denote stations.

The Bermondsey cluster is known locally as the 'Bermondsey Beer Mile' (ES Going Out 2014). This is a slight misnomer as the area runs almost exactly two miles along the railway tracks leading out from London Bridge Station in the north-west, beginning at the Southwark Brewing Company and ending with Fourpure (located near South Bermondsey Station). Figure 7 shows that the breweries are all situated along the railway line - indeed of the 59 stand-alone (non-brewpub) breweries operating in London in 2016, 30 are located within 100m of a railway line - most of these in 'railway arches' underneath the railway itself (many of the others are found on post-war industrial estates, but this is a geography that we will not explore in this paper). 


\section{Railway Arches}

The railway arch is an important element of the hyperlocal geography of brewing in Bermondsey (examples of brewing industry sites in railway arches are illustrated in Supplementary Information) and in some other locations in London (Hackney, Herne Hill/Brixton). In these areas, it is key to explaining how a frequently space-intensive industry like brewing has been able to penetrate central London, where land values and rents are generally extremely high and space is usually at a premium. During the industrial revolution, viaducts were constructed of brick arches to support many of the railways running into central London (Hendey, 1987). These urban viaducts have faced much criticism, mainly because of their intrusive aesthetic brutalism and their tendency to form physical barriers to movement, segregating large areas in the city (Haywood, 2008). Historically, they have also been problematic spaces - while many are quite large, they were often unsuitable for many activities because of issues such as noise and vibration, water penetration, poor ventilation, and lack of natural daylight (Hendey, 1987). Thus, despite large numbers of arches located in the centre of cities, they have "acquired a somewhat dubious image - notoriously as the haunt of car-breakers and such small time enterprises... generating a below-potential rent." (Hendey, 1987, p. 38). However, it is precisely these low rental costs and favourable central locations, coupled with an abundance of space, that make railway arches particularly popular locations for many of London's new breweries - indeed the low rent associated with railway arches was cited as one important motivating factor for the particular choice of site by one owner of a "Beer Mile" brewery, in an informal conversation with the authors.

We were not able to identify a historic link between railway arches and the brewing process itself (although there is a link with storage potential), so this development seems to be something rather new. The low cost and abundance of space has resulted in recent refurbishment of many arches around London; these are now lined with corrugated metal giving a degree of protection from the bare and often damp brickwork behind. This treatment makes the spaces more hygienic and habitable for the production of food and drink products.

Breweries are not alone as recent inhabitants of railway arches, whose renovation seems to have been a conscious decision by Network Rail, which owns and manages them, to diversify the business ecosystem within them: "the company wants to encourage the growth of such hubs, where firms with overlapping interests can mutually reinforce each other" (Tran 2016: n.a.). Prior to the Beer Mile, Maltby 
Street Market was established in Bermondsey in around 2010, and recently the Spa Terminus project ${ }^{16}$ has brought together a range of food and drink producers in the area. Thus, to characterise this as simply a 'beer affair' would be misleading, as the beer mile is a later adjunct. Beer writer Pete Brown attests in the documentary, Original Gravity (Karaca, 2015), that 'beer actually cottoned on to this particular trend', highlighting the growing standards (and price) of food within places like Borough Market near London Bridge station. The Beer Mile has become an attraction in and of itself, to both beer aficionados and brewers. In the informal conversation noted above, the brewer revealed that establishment of the Beer Mile had been a factor in their decision to move in, in 2013, and reported that enough money was made selling beer directly to customers at weekends to cover the running costs, with sales outside the weekend (to pubs, restaurants and shops) being pure profit.

The direct connection between the brewer and the customer is something that characterises the new breweries in Bermondsey, as well as in London more widely. All breweries along the Beer Mile open 'tap rooms ${ }^{17 \prime}$ at the weekends when active brewing is not taking place, selling beer both to drink on the premises and to take away. Brewery taps are not a new phenomenon in brewing, but whereas brewery taps were traditionally pubs attached to breweries, these new tap rooms are temporary with trestle tables and benches arranged amongst the brewing paraphernalia. While tap rooms in the arches benefit from a 'post-industrial' feel which adds to the experience, the act of buying freshly brewed beer from source, just feet from where it was produced, and the resulting direct interaction with the producers, are more important. This connection between producer and customer has much more in common with the recent proliferation of Farmers' Markets and their ability to reinforce "notions of local, quality, authenticity and legitimacy" (Smithers et al., 2008, p. 338) through these interactions, than has been the case in the recent history of the brewing industry, where (large) brewers have more often sold their beer through third parties (pubs and shops).

In Bermondsey, we can attribute at least some of the reason for the clustering to the abundance of suitable and affordable space underneath the railway arches, as well as the burgeoning local food scene and the many visitors and tourists this brings at the weekend. As highlighted by Partizan Brewery's head brewer (Spencer and Doherty, 2013), people who are prepared to search for 'nice things to eat',

\footnotetext{
${ }^{16} \mathrm{http}: / /$ www.spa-terminus.co.uk/

${ }^{17}$ The Kernel Brewery's tap room was first to open but also the first to close (in September 2015)
} 
also now want 'nice things to drink'. These are customers who place value on the embedded notions of local, quality, authenticity and legitimacy that Smithers et al. (2008) highlight in their study of Farmers' Markets and which are reinforced when consumers and producers connect directly. While it could be argued that the Bermondsey experience (in terms of the sheer number of food producers and the number of visitors) is unique, the connection between producer and consumer through direct sale has been reproduced in other areas in London, with virtually all new breweries now opening tap-rooms and occasionally involving craft food producers - for instance, Oh My Dog! Hotdogs at Beavertown in Tottenham Hale or Dough Boys pizza and Choi Boys at the Wildcard Brewery (McCoy, 2016).

The central locations made possible by the railway arches mean that the Bermondsey breweries are much more able to connect with the larger potential tourist and visitor market in central London. However, while this can help explain the absolute location of breweries in the Beer Mile, their relative proximity to each other is explained by other factors.

Economies of cooperation

One of our early hypotheses, based on evidence from America, was that terroir and locational uniqueness would be important for new breweries in London and could lead to their dispersal. It has become apparent that new breweries in London cluster, suggesting that there are far greater advantages to be gained from proximity. The modern influx of breweries to Bermondsey began with Kernel in 2009. They were followed by Partisan, Brew by Numbers and Anspach \& Hobday in 2012, and with Fourpure and the Southwark Brewing Company in 2013. Both Brew by Numbers and Anspach \& Hobday attribute the recent growth of this area in part to the arrival of Kernel. However, while Kernel's early success demonstrated to others that a viable brewery business could be built in the area, it was probably the sharing of skills (they helped teach Anspach \& Hobday how to brew) and equipment (Kernel gave Partisan their old equipment [Spencer and Doherty 2013; Hawkes 2013]) that had even more of an impact. One of the very noticeable features of the culture swirling around the modern breweries in London is the air of cooperation. Another example akin to the Kernel anecdote is that until very recently when Bullfinch relocated to Herne Hill, they shared brewing equipment with Anspach \& Hobday (ES Going Out, 2014). The film Original Gravity (Karaca, 2015) testifies that this sharing and cooperative culture is not exclusive to Bermondsey, and brewers in other areas have noted how they share 
equipment, each other's ingredients, and trade recipes. This collaborative attitude can be further witnessed through the beer itself in the modern phenomenon of 'beer collaborations' (Clarke, 2010) where brewers team up to produce joint brews. In an interview with The Guardian newspaper (Hawkes, 2013), Evin O'Riordain (founder of Kernel) highlighted the huge importance of positive community support, cooperation and constructive criticism in the new wave of London brewing, citing his joining of the London Amateur Brewers group ${ }^{18}$ as being instrumental in helping him learn how to brew well.

Far from viewing each other as competitors, ${ }^{19}$ brewing in London is collegiate. This is a community with the same overriding goal - to produce excellent beer. The London Brewers Alliance ${ }^{20}$ (now incorporating most of the new breweries in the city and some of the old), established itself in 2010 with a number of aims including "co-operating with any other body that is deemed to have similar aims [promoting excellence in brewing in the city]" and "supporting the improvement of brewing skills among the membership." The pursuit of profit is not a primary motivating factor (indeed the sale of the Camden Town Brewery - one of the first of the new-wave of London craft breweries - to AB InBev in an apparently profitseeking multi-million pound deal in late 2015 drew the ire of customers and fellow brewers alike (Anderson and Martin, 2015)). It is thus not surprising that breweries cluster in areas like the Bermondsey, taking advantage of what we might term 'economies of cooperation' - the very real benefits afforded by sharing resources (including equipment, ideas ${ }^{21}$, knowledge, workforce and customers) rather than competing with one another. Collaboration has combined with other factors in Bermondsey to form a particularly tight and strong cluster.

To some extent, this might counter some established economic theory. Porter (1979) sets out a framework for understanding industrial strategy where pressures from competitive forces eventually lead to producers jockeying for position in relation to each other, followed by buyouts and mergers. This is what

\footnotetext{
18 https://londonamateurbrewers.co.uk/

${ }^{19}$ As was the case with London breweries in the past where, for example, during the eighteenth century the industrialisation of brewing in London led to a reduction from around 200 brewers in the 1690s, to just 12 firms dominating the market (Krenzke, 2014)

${ }^{20} \mathrm{http} / / / \mathrm{www}$.londonbrewers.org/about-us/

${ }^{21}$ In 2016, the Scottish independent brewer, Brewdog - perhaps the largest and most successful of all new craft breweries in Britain - released the recipes for all of the 215 beers they had brewed to date (https://www.brewdog.com/diydog) The release of this kind of intellectual property so that competitors could potentially reproduce any of their products perhaps says more than anything else about the culture and mentality of modern brewing in Britain.
} 
happened to the London brewing industry in previous centuries where only the largest survived, but as we will see in the next section there are features of the current macroeconomic landscape inhabited by brewing that create conditions somewhat different from those in previous decades. In addition, given the small size of most new breweries in London, the potential pool of contented customers is (for the time being) large enough to dampen the usual competitive forces. As yet, there are no obvious signs that breweries are competing for customer resources and so for the present, cooperation is the dominant force.

Macro-economics: Progressive beer duty and the financial crash

At the same time as brewing took off in Bermondsey in 2009, other breweries began to emerge across London. It is difficult to ascribe a single reason for this sudden burst, but there are two main contributing economic factors which can together be viewed as influential.

For much of the last century, the trend in industrial production of any product (cars, clothes, electronics etc.) has been towards economies of scale. Scale offers a number of advantages: buying raw materials in large bulk volumes is often cheaper; loans for investing in equipment are offered at better rates to larger companies; risks can be spread; per-unit costs of production are reduced. Because of these various advantages, for a long time the big breweries were able to produce beer far more cheaply than their smaller competitors, meaning they were able to dominate. However, a significant part of the cost of a pint of beer in the UK is, in fact, tax imposed by the government - beer duty - and in 2002, the then Chancellor of the Exchequer, Gordon Brown, introduced a new progressive beer duty (Lucas, 2010). This meant that breweries producing under 30,000 hectolitres (3,000,000 litres) a year (about 353 barrels of beer per week) received tax relief at $50 \%$ (or around $£ 45$ per barrel) on the first 5,000 hectolitres (59 barrels a week) brewed (SIBA, 2005). For a barrel of beer retailing at around $£ 150$ this effectively negates the cost of production for small brewers when competing with large producers paying full tax. In one fell swoop the government neutralised the advantages of economies of scale in brewing and laid the foundations for a far more diverse brewing landscape.

However, while the progressive beer duty was introduced in 2002, its effect was not immediate. In London, it was almost a decade before a serious growth in the number of breweries was noticeable, so while the foundations were laid, other 
factors were at play. Pete Brown (Karaca, 2015) cites anecdotal evidence of the financial crash of 2008 leading to a number of people re-evaluating their career choices, with a number opting for brewing. While this might not be the case for the Bermondsey cluster (where brewers were variously undergraduate students, cheese sellers and big brewery office employees), there may then have been a sense that the financialised capitalist world order was not the way forward. Microbreweries are the antithesis of big multinational companies and the very hands-on nature of the work, as highlighted by Thurnell-Read (2014), can be very much viewed as an active antidote to the modern industrial order of disembodied mass production. Therefore, it is probable that the growth of new breweries in London has partly been a reaction to market capitalism and big corporations.

\section{Foreign Influence and modern technology}

One noticeable feature of the new breweries is the huge variety in the styles of beer that are brewed. Traditional London beer is cask ale. A cask ale is fermented in open vessels, does not use nitrogen or carbon dioxide in its pouring, tends to have an alcohol content of 3\%-5\%, and is kept and served at 'cellar' temperature. Much of the new beer brewed in Bermondsey (and across London) is not cask beer but is served from kegs. Keg beer is brewed in sealed vessels, kept at lower temperatures, often has a higher alcohol content, and is poured under pressure with the aid of carbonating gasses.

Kegged beer is traditionally associated with lagers. However, intensely hopped strong beer served from kegs began to come to prominence in the USA with the rise of its craft beer industry over the last 20 years or so. The American Style Pale Ale or A/IPA (which bears little resemblance to the original cask India Pale Ale brewed for export to India from Britain upon which it is styled) has become immensely popular - as exemplified by the rise of Brewdog and their signature, American style, 'Punk IPA'. In Bermondsey and across London while cask beer is still brewed and popular, these Pale Ales and IPAs are core to many breweries, along with other kegged beers drawing influence from traditional sour Belgian Lambic styles, French saisons, porters, stouts and dark or black lagers. This huge variety is driven by foreign experiences, and new flavours and beer styles are cited as motivating factors for a number of the new brewers in Bermondsey (certainly Brew By Numbers, Partizan and Kernel).

An important facilitator in the proliferation of kegged beer is a recent change in the technology used for storing it; a change from the traditional heavy, metal barrel to lighter (cheaper) plastic vessels. The KeyKeg is a popular brand of plastic 
vessel used in many craft beer breweries. Introduced to the market in 2006, these have a 'two-compartment system, with a laminated inner bag inside a high-tech PET pressure vessel'22. They are designed to be stackable, and are more easily transportable and simple to use than traditional kegs. Although originally used in the wine industry, modern breweries have utilised these kegs to good effect. They are a reliable form of storage; whereas before, some styles of beer would not last long or be transported far, it is now possible to brew new, more temperamental, beers with more confidence that they will be still be fit for sale some time and distance from the brewery.

\section{Market}

The final piece in the explanatory puzzle for the growth in brewing in Bermondsey relates to the market for beer. Part of the market story has already been discussed, in that Bermondsey is now a popular food and drink market and most brewers across London now sell direct through tap rooms. The demographic profile of these customers is younger and more affluent than the general population (P. Brown, 2015) and as the 2011 Census attests, they are spatially more prevalent in the centre of London than the periphery.

While it would not be difficult to sell further afield (and indeed many do), many breweries do not have large distribution networks - many distribute beer themselves with the aid of a single van. In our informal conversations with one brewer, we were told that local (within London) pubs were their main customers (a situation apparently shared by other brewers in the city, as recounted by Hackney Brewery's head brewer in the Original Gravity (Karaca, 2015)). Bars and restaurants are other regular sales outlets in the city, but these are also overwhelmingly concentrated in the centre - one of the Bermondsey cluster breweries revealed that they sold beer to high-end restaurants in the 'Shard' tower less than a kilometre from London Bridge.

\section{Conclusions}

The number of breweries in London has risen rapidly since the turn of the millennium. In this paper, we have investigated the spatial and temporal evolution of the rise of these new breweries in London, focusing particularly on Bermondsey. Our analysis has shown that brewing is once again a central London activity, with breweries drawn to and clustering in the boroughs of Southwark, Tower Hamlets, Islington, Hackney and Lambeth for a number of interacting

\footnotetext{
22 https://www.keykeg.com/en/keykeg-products-beverage-distributors
} 
reasons. Our early hypothesis was that any evidence of spatial patterning would reveal the extent to which the forces of local identity and branding were a central concern to the new wave of brewers; our analysis reveals that locational uniqueness (certainly at the hyper-local level - although 'London' is prominent in the branding of many breweries) is of secondary concern when compared to the many advantages afforded by clustering closely in space.

In our Bermondsey case study, we were able to highlight the role of the railway, other (influential) breweries, the sharing economy, modern technologies, macroeconomic conditions and the market in facilitating the growth of new breweries in this area. The story of Kernel arriving in Bermondsey under a railway arch in 2009, after the financial crisis and after the head brewer had become inspired by travel abroad and encouraged by a local community of enthusiasts, is emblematic rather than typical, but contains elements that many brewers in the city will recognise in their own stories. Not all breweries follow this same path, but many encroach upon it along the way.

It is only with a recent programme of renovations by Network Rail that rail arches have been able to become spaces of brewing, leading to a distinctive physical geography for around half of the new breweries in the city. This is seen particularly clearly in Bermondsey. A great number of customers will purchase their beer directly from brewers in temporary tap-rooms in the breweries themselves, with brewers taking advantage of a shift in the buying habits of customers, away from anonymous mass production and towards the authenticity, legitimacy and quality of craft production. Breweries have not been alone in exploiting the renovation of these spaces and shift in consumer attitudes, and find themselves amongst street food and farmers' markets. Hence, Bermondsey has seen the recent birth of both the 'Bermondsey Beer Mile' and the Maltby Street Market.

Another key element of the Bermondsey story is what we have termed 'economies of cooperation'. This camaraderie between the brewers means that equipment, ideas, knowledge and customers are all shared to the benefit of all. In our case study, Kernel played a central role in the cooperation economy of Bermondsey, but other examples abound across the capital.

This study is only the beginning of the story. We cannot be sure how the brewing landscape of Bermondsey or London will continue to evolve. There are signs that fewer breweries opened in 2016 than in 2014 or 2015, in which case, is this a slowdown? Has London's capacity to support a finite number of microbreweries been met? How sustainable is the London beer drinkers' thirst for craft beer? More 
work needs to be carried out to understand the interactions between the brewers and their market to develop this much more nuanced picture and understand what the prospects for the new brewing industry might be in the future. We are compelled to observe that the UK is not alone in the growth of 'craft' breweries. Much research has already been carried out on the craft brewing industry in the USA, but Asia, Latin America and much of Europe also appear to be following suit, so the evolving global geography of brewing is likely to continue to be of interest to scholars.

\section{Acknowledgements}

We would like to thank the two anonymous reviewers and Editor Keith Richards for very helpful comments and suggestions on earlier drafts of this paper. We would also like to thank George Breckenridge for his help in digitising some of the brewery data which appeared in this analysis. 


\section{References}

Anderson E and Martin B 2015 Backlash after Camden Town Brewery sold to world's biggest drinks company AB InBev The Daily Telegraph 22 Nov (http://www.telegraph.co.uk/finance/newsbysector/retailandconsumer/lei sure/12062304/Backlash-after-Camden-Town-Brewery-sold-to-worldsbiggest-drinks-company.html) Accessed 15 May 2017

Anselin L 1995 Local Indicators of Spatial Association-LISA Geographical Analysis 27 (2) 93-115 doi:10.1111/j.1538-4632.1995.tb00338.x

Baddeley A, Rubak R T and Raynaud E 2015 Spatial Point Patterns: Methodology and Applications with R. London: Chapman and Hall/CRC Press. URL (http://www.crcpress.com/Spatial-Point-Patterns-Methodologyand-Applications-with-R/Baddeley-Rubak-Turner/9781482210200/)

Brown M 2015 London Brewed: A Historical Directory of the Commercial Brewers of London from circa 1650 Brewery History Society Longfield UK

Brown P 2014 The Cask Report 2014-2015 (Volume 8) Cask Marque

Brunsdon C and Comber L 2015 An introduction to R for spatial analysis \& mapping SAGE, Los Angeles

Cabras I 2015 British Beer - A report on the 2015 members' survey of the Society of Independent Brewers The Society of Independent Brewers (http://www.siba.co.uk/forms/SIBA_Beer\%20Report_lores.pdf) Accessed 22 June 2016

Clarke J 2010 Beer Collaborations Imbibe 10 Feb (http://imbibemagazine.com/Beer-Collaborations) Accessed 15 May 2017)

Danson M, Galloway L, Cabras I and Beatty T 2015 Microbrewing and entrepreneurship: The origins, development and integration of real ale breweries in the UK International Journal of Entrepreneurship and Innovation Management 16 135-144 doi:10.5367/ijei.2015.0183

Dixon C 1978 The Changing Structure of the British Brewing Industry Geography 63 108-113

Ester M, Kriegel H-P, Sander J and Xu X 1996 A density-based algorithm for discovering clusters in large spatial databases with noise AAAI Press pp. 226-231

ES Going Out 'Bermondsey Beer Mile's craft beer crawl' Evening Standard (10 Apr 2014) (http://www.standard.co.uk/goingout/bars/bermondsey-beer-milescraft-beer-crawl-9250311.html) Accessed 15 May 2017. 
Flack W 1997 American Microbreweries and Neolocalism: "Ale-ing" for a Sense of Place Journal of Cultural Geography 16 37-53 doi:10.1080/08873639709478336

Goreaud F and Pélissier R 1999 On Explicit Formulas of Edge Effect Correction for Ripley's K-Function Journal of Vegetation Science 10 433-438. doi: $10.2307 / 3237072$

Hawkes W 2013 How to start your own brewery The Guardian 21 July (https://www.theguardian.com/lifeandstyle/2013/jul/21/how-to-start-ownbrewery) Accessed 15 May 2017

Haywood R 2008 Underneath the Arches in the East End: An Evaluation of the Planning and Design Policy Context of the East London Line Extension Project Journal of Urban Design 13 361-385 doi:10.1080/13574800802320863

Hendey C 1987 Railway arches Structural Survey 5 32-38 doi:10.1108/eb006248

Hennig C 2015 fpc: Flexible Procedures for Clustering. R package version 2.1-10. (https://CRAN.R-project.org/package $=\mathrm{fpc}$ )

Karaca K 2015 Original Gravity (http://kevinkaraca.co.uk/original-gravity-film/) Accessed 15 May 2017.

Knowles T and Egan D 2001 The Changing Structure of UK Brewing and Pub Retailing. International Journal of Wine Marketing 13 59-72 doi:10.1108/eb008720

Krenzke J R 2014 Change is Brewing: The Industrialization of the London BeerBrewing Trade, 1400-1750 Loyola University Chicago

Lucas L 2010 Breweries find craft ale is not just small beer FT.com 21 Dec (https://search-proquestcom.libproxy.ucl.ac.uk/docview/819686578?accountid=14511) Accessed 15 May 2017

McCoy F 2016 London's tap rooms: the new wave of beer halls Evening Standard 17 Feb (http://www.standard.co.uk/goingout/bars/beer-hallsa3182471.html) Accessed 15 May 2017

Moran P A P 1950 Notes on Continuous Stochastic Phenomena Biometrika 37 17-23 doi:10.2307/2332142

Openshaw S 1984 The modifiable areal unit problem Geo Books Norwich UK Openshaw S, Charlton M, Wymer C and Craft A 1987 A Mark 1 Geographical Analysis Machine for the automated analysis of point data sets International journal of geographical information systems 1 335-358 doi:10.1080/02693798708927821 
Openshaw S, Craft A W, Charlton M, and Birch J M 1988 Investigation of leukaemia clusters by use of a Geographical Analysis Machine Lancet 6 272-273.

Porter M E 1979 How Competitive Forces Shape Strategy Harvard Business Review (https://hbr.org/1979/03/how-competitive-forces-shape-strategy) Accessed 15 May 2017

Schnell S M and Reese J F 2003 Microbreweries as Tools of Local Identity Journal of Cultural. Geography 21 45-69 doi:10.1080/08873630309478266

Society of Independent Brewers 2010 Local Brewing Industry Report 2010

Society of Independent Brewers 2005 Excise Duty for Small Brewers

Smithers J, Lamarche J and Joseph A E 2008 Unpacking the terms of engagement with local food at the Farmers' Market: Insights from Ontario Journal of Rural Studies 24 337-350 doi:10.1016/j.jrurstud.2007.12.009

Spencer M and Doherty A 2013 Andy Smith Makes Beer (https://vimeo.com/66575506) Accessed 15 May 2017

Thurnell-Read T 2014 Craft, tangibility and affect at work in the microbrewery Emotion Space and Society 13 46-54 doi:10.1016/j.emospa.2014.03.001

Unwin P T H 1991 Wine and the vine: an historical geography of viticulture and the wine trade Routledge London and New York.

Tran M 2016 Open for business: the railway arches serving customers as well as trains The Guardian 7 Feb 2016

(https://www.theguardian.com/society/2016/feb/07/open-for-businessthe-railway-arches-serving-customers-as-well-as-trains) Accessed 15 May 2017 